\title{
Comportamento Proativo nas Organizações: O Efeito dos Valores Pessoais
}

Proactive Behavior In Organizations: The Effect Of Personal Values

Comportamiento proactivo en las organizaciones: el efecto de los valores personales

Meiry Kamia

Universidade Presbiteriana

Mackenzie

Juliana Barreiros Porto

Universidade de Brasília

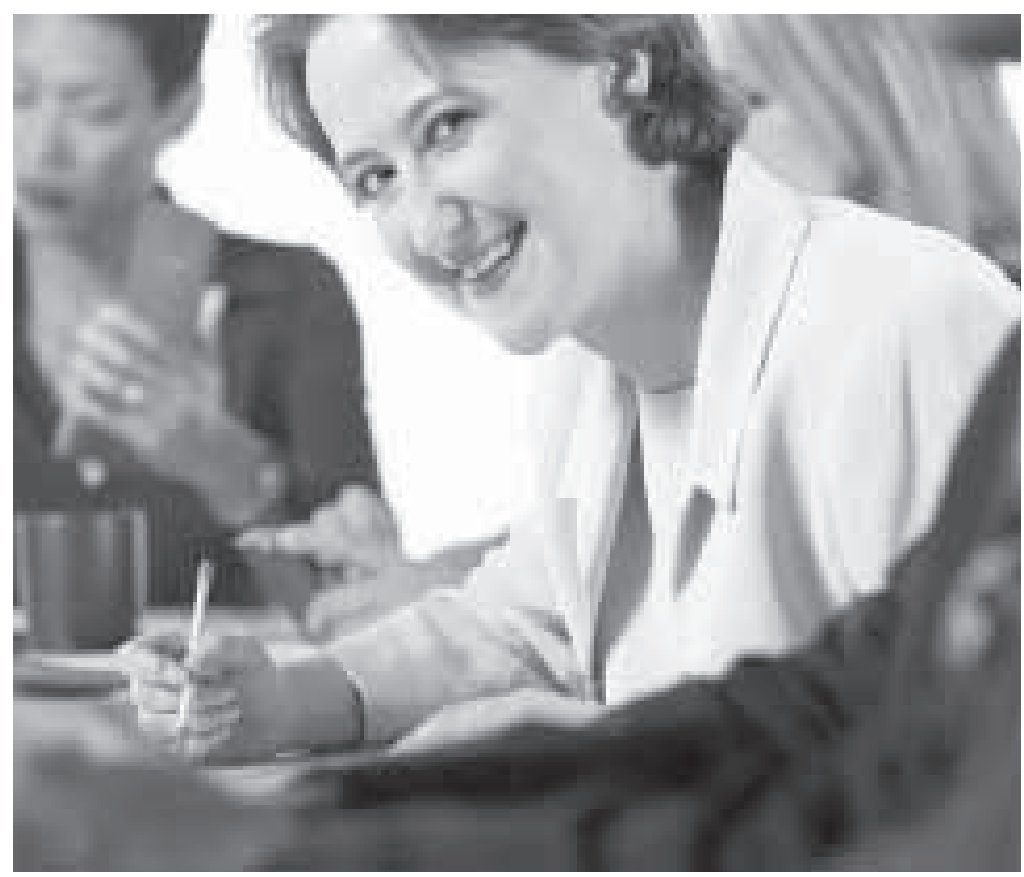


Resumo: O comportamento proativo é definido como um conjunto de comportamentos extrapapel em que o trabalhador busca espontaneamente mudanças no seu ambiente de trabalho, soluciona e antecipa-se aos problemas, visando a metas de longo prazo que beneficiam a organização. Este estudo teve por objetivo investigar a relação entre os valores pessoais e o comportamento proativo nas organizações. Foram utilizados como instrumentos de medida o Personal Values Questionnaire e a Escala de Comportamento Proativo nas Organizações, ambos já validados para o Brasil. Após a eliminação dos casos extremos, a amostra ficou constituída por 325 funcionários de diferentes organizações. A análise de regressão linear revelou que os valores predizem significativamente os comportamentos proativos, apontando uma relação positiva do tipo motivacional estimulação $(B=0,205, p<0,01)$ e universalismo/benevolência $(B=0,302, p<0,01)$ com proatividade, e negativa com o tipo motivacional tradição ( $B=-0,189, p<0,01)$, de acordo com o previsto pelo referencial teórico. As implicações para os estudos na área são discutidas.

Palavras-chaves: Valores. Atitudes do empregado. Desempenho no trabalho. Comportamento organizacional.

Abstract: Proactive behavior is a set of extra role behaviors in which the worker spontaneously seeks for change in his work environment, solves and anticipates problems, aiming long-term goals that benefit the organization. This paper investigates the relationship between personal values and proactive behavior in organizations. A survey was conducted using the Personal Values Questionnaire and the Proactive Behavior in Organizations Scale, both validated in Brazil. After outlier deletion, 325 employees answered the questionnaire. The linear multivariate regression pointed to a significant prediction of values, and indicated a positive relationship between the motivational types of stimulation $(B=0,205, p<0,01)$ and universalism/benevolence $(B=0,302, p<0,01)$ with proactive behaviors, and a negative relationship with the motivational type of tradition $(B=-0,189, p<0,01)$. The results were in accordance with the literature revised. Implications for future studies are discussed.

Keywords: Values. Employee attitudes. Job performance. Organizational behavior.

Resumen: El comportamiento proactivo es definido como un conjunto de comportamientos extraordinarios a través de los cuales el trabajador busca espontáneamente cambios en su ambiente de trabajo, soluciona y se anticipa a los problemas, con el objetivo de alcanzar retos de largo plazo que benefician la organización. Este estudio ha tenido como objetivo investigar la relación entre los valores personales y el comportamiento proactivo en las organizaciones. Se han llevado a cabo como instrumentos de medida el Personal Values Questionnaire y la Escala de Comportamiento Proactivo en las Organizaciones, ambos ya habilitados en Brasil. Luego de la eliminación de los casos extremos, la muestra quedó conformada por 325 funcionarios de distintas organizaciones. El análisis de regresión lineal ha revelado que los valores predicen significativamente los comportamientos proactivos, apuntando hacia una relación positiva del tipo motivacional estimulación $(B=0,205, p<0,01)$ y universalismo/benevolencia $(B=0,302, p<0,01)$ con proactividad, y negativa con el tipo motivacional tradición $(B=-0,189, p<0,01)$, con arreglo a lo previsto por el referencial teórico. Las implicaciones para los estudios en el área son discutidas.

Palabras clave: Valores. Actitud Del empleado. Redimiento laboral. Comportamiento organizacional.

Pesquisas sobre proatividade ganharam força nos últimos quinze anos em função do aumento da competitividade e da complexidade da economia global. Bateman e Crant (1993) justificam essa ênfase a partir dos benefícios trazidos para as organizações pelos comportamentos que mostram iniciativa, capacidade de planejar ações e de agir além dos limites das tarefas. Nesse contexto, o comportamento proativo tem se mostrado um dos determinantes críticos para o sucesso organizacional.

O comportamento proativo pode trazer resultados benéficos tanto para o indivíduo como para a organização (Bateman \& Crant,
1993). No nível individual, a proatividade está relacionada com realização pessoal, com potencial para liderança transformacional e com atividades cívicas e extracurriculares de estudantes (Bateman \& Crant, 1993). No nível organizacional, a proatividade pode ser um importante elemento da performance de serviços da empresa (Jong \& Ruyter, 2004) e, em consequência, pode ter um impacto positivo no seu faturamento (Bateman \& Crant, 1999). A proatividade da organização também pode ser medida por meio do número e da frequência de introdução de novos produtos, serviços e processos, da quantidade de recursos dedicados à inovação e da frequência em que a firma é a primeira ou 
O nível de proatividade da firma reflete sua capacidade de criar demandas e de dirigir mercados, e diferencia empresas líderes e seguidoras em sua indústria (Bateman \& Crant, 1999). a segunda a se posicionar diante do mercado. O nível de proatividade da firma reflete sua capacidade de criar demandas e de dirigir mercados, e diferencia empresas líderes e seguidoras em sua indústria (Bateman \& Crant, 1999).

O foco deste estudo é a proatividade em nível individual e nas variáveis que podem promover esse comportamento. A literatura aponta fatores individuais e ambientais como antecedentes do comportamento proativo no nível do indivíduo (Crant, 2000). No caso dos fatores individuais, pode-se encontrar pesquisas sobre o efeito da personalidade (Crant, 2000) e recuperação e engajamento no trabalho (Sonnentag, 2003), e, no caso dos fatores ambientais, podem ser variáveis a cultura organizacional (Crant, 2000), o trabalho autônomo, a confiança nos parceiros de trabalho e o suporte da supervisão (Parker, Williams, \& Turner, 2006).

Segundo Crant, os comportamentos proativos envolvem "desafiar o status quo, mais do que se adaptar passivamente às condições atuais" (2000, p. 436). Sendo assim, é possível supor que comportamentos proativos ativem os valores individuais ao evidenciar uma situação de conflito entre promover ações de abertura à mudança e, em consequência, desestabilizar o status quo, ou evitar essas ações e promover a conservação. Os valores, portanto, podem ser um dos preditores de proatividade. Este estudo objetivou investigar a influência dos valores pessoais sobre o comportamento proativo. Conhecer quais valores se relacionam positivamente com o comportamento proativo pode beneficiar organizações que buscam atrair e reter funcionários proativos, por meio da estimulação de valores que estejam positivamente relacionados, em detrimento dos valores que estejam negativamente relacionados à proatividade.

\section{Comportamento proativo}

Na literatura acadêmica, a proatividade tem sido um conceito de difícil definição, além de ser confundida com cidadania organizacional, inovação e comportamento de expressão (voice behavior). De acordo com Crant (2000), a dificuldade em diferenciar o conceito ocorreu pelo fato de os pesquisadores terem adotado diferentes enfoques na tentativa de identificar antecedentes e consequentes do comportamento proativo, e isso trouxe certa confusão para encontrar uma definição única do conceito nos diversos estudos. Apesar das divergências, existe um consenso entre as duas definições mais adotadas nos estudos atuais, a de Bateman e Crant (1993) e a de Frese, Kring, Soose e Zempel (1996).

Bateman e Crant (1993) definiram a proatividade como um protótipo de pessoa que altera o ambiente, não se deixando limitar pelas forças situacionais. Pessoas de personalidade proativa buscam oportunidades de mudanças visando a melhorias, mostram iniciativa, antecipam e solucionam problemas, são ativas, perseveram até alcançar seus objetivos, mostram-se mais ativamente envolvidas com o mundo a sua volta e desenvolvem atividades profissionais que ressaltem redes interpessoais de trabalho que potencializam suas carreiras (Crant, 1996).

Em 1996, Frese et al. propuseram o conceito de iniciativa pessoal como

uma síndrome comportamental que resulta em uma tomada de ação individual e de iniciativa, voltada para o trabalho, e que vai além do que é formalmente requerido em um dado trabalho. Mais especificamente, a iniciativa pessoal é caracterizada pelos seguintes aspectos: 1) é condicionada à missão da organização, 2) tem foco de longo prazo, 3) possui metas direcionadas e ação orientada, 4) é persistente em face às barreiras e contratempos, e 5) iniciativa e proatividade (p. 38, tradução nossa)

No ano seguinte, Frese, Fay, Hilburger, Leng e Tag (1997) assumiram que existia uma coincidência entre a escala de personalidade proativa de Bateman e Crant (1993) e o conceito de iniciativa proposto por Frese et 
al. (1996), e os resultados da pesquisa de 1997 reforçaram a existência de um alto grau de variância comum entre eles. Por esse motivo, Frese et al. (1997) enfatizaram que a formulação de um construto de iniciativa pessoal se fazia necessária. A posição dos autores nesse artigo foi que a iniciativa pessoal possuía uma relação importante com o comportamento observável. Crant (2000) também sugeriu a existência de um construto em comum, uma vez que ambos os construtos possuíam tendências comportamentais dirigidas ao comportamento proativo.

Enquanto a definição do construto comum não surgia, diversos estudos foram sendo realizados (Bateman \& Crant, 1999; Claes, Beheydt, \& Lemmens, 2005; Crant, 2000; Jong \& Ruyter, 2004; Parker et al., 2006; Sonnentag, 2003) considerando o construto de comportamento proativo proposto por Bateman e Crant (1993), e outros estudos (Fay \& Frese, 2001; Frese et al., 1997; Frese et al., 1996; Frese, Teng, \& Wijnen, 1999; Rank, Pace, \& Frese, 2004) seguiram considerando o construto de iniciativa pessoal proposto por Frese et al. (1996).

Kamia e Porto (2007) sustentam, a partir da análise das definições dos conceitos de iniciativa e proatividade, que se trata do mesmo construto com denominações diferentes, apesar de a operacionalização dos conceitos ser feita de forma diferente. Enquanto Crant (2000) faz uma medida de personalidade, Frese et al. (1997) usam uma medida comportamental. As autoras defendem o uso do termo comportamento proativo com medida comportamental.

Com base na análise feita por Kamia e Porto (2007), este estudo define o comportamento proativo nas organizações como o conjunto de comportamentos extrapapel em que o trabalhador busca espontaneamente mudanças no seu ambiente de trabalho visando a metas de longo prazo que beneficiam a organização. Tais comportamentos são restritos à organização, podem manifestar-se de diferentes formas no contexto de trabalho e envolvem: 1) busca ativa por oportunidades de mudança, 2) planejamento e execução de ideias e 3) enfrentamento de obstáculos.

\section{Antecedentes de comportamento proativo}

Em 2000, Crant fez uma análise dos estudos científicos sobre antecedentes e consequências do comportamento proativo, nos quais encontrou uma literatura com diferentes enfoques sobre entendimento, medidas e definição da proatividade. Nesse estudo, Crant sugeriu um modelo teórico em que se colocam diferenças individuais e fatores contextuais como antecedentes do comportamento proativo. No caso das diferenças individuais, elas podem ser divididas em: a) construtos do comportamento proativo (personalidade proativa, iniciativa pessoal, autoeficácia e provocação de mudanças), cuja estrutura é especialmente designada para capturar a disposição em direção ao comportamento proativo ou ao potencial para comportamentos proativos, e b) outras diferenças individuais (ex.: envolvimento no trabalho, metas orientadas, desejo de feedback, necessidade de realização) que consistem em variáveis associadas a comportamentos proativos específicos. Os fatores contextuais também são considerados antecedentes, porque estão associados à decisão de se comportar de forma proativa. Alguns exemplos de antecedentes contextuais seriam: a cultura organizacional, as normas organizacionais, as sugestões operacionais, o suporte gerencial e o ajuste público ou privado. Crant não testa empiricamente $\mathrm{o}$ modelo, mas apresenta um bom panorama das pesquisas já realizadas até aquela época.

Estudos como os de Bateman e Crant (1993), Frese et al. (1997) e Sonnentag (2003) focam os antecedentes individuais. Outros, como os de Frese et al. (1996), Crant (2000), Fay e Frese (2001) e Parker et al. (2006) consideram antecedentes individuais juntamente aos contextuais. A maioria das pesquisas utilizou escalas ou questionários como instrumentos de medida, amostra de trabalhadores e, 
como procedimento estatístico, a análise de regressão multivariada. A seguir, são relatados esses estudos.

O estudo de Bateman e Crant (1993) relacionou a escala de personalidade proativa com os domínios de personalidade do big five: neuroticismo, extroversão, abertura para novas experiências, socialização e realização, com três traços de personalidade (lócus de controle, necessidade de realização e necessidade de dominância) e com três variáveis critérios (atividades cívicas e extracurriculares, natureza de suas realizações pessoais e liderança transformacional). Os resultados apontaram uma correlação positiva com realização (ou vontade) $(r=0.43, p<0.01)$ e extroversão $(r=$ $0.25, p<0.01)$. Não houve uma correlação significativa com abertura, nível de socialização, neuroticismo e lócus controle, mas foi significativa com necessidade de realização $(r=0.45, p<0.01)$ e com necessidade de dominância $(r=0.43, p<0.01)$. Com relação às variáveis critérios, uma vez controlado o efeito da variável nível de autoconsciência (capacidade do indivíduo de se perceber), a proatividade mostrou relação positiva com atividades extracurriculares que objetivam mudanças construtivas (parcial $r=0.29, p$ $<0.01$ ), realização pessoal (parcial $r=0.21$, $\mathrm{p}<0.05$ ) e liderança transformacional (parcial $r=0.33, p<0.01)$.

Frese et al. (1997) desenvolveram uma pesquisa longitudinal em que foi observada a relação entre iniciativa e necessidade de realização, orientação para agir, estratégias de enfrentamento, planejamento de carreira, execução de planos, tempo para encontrar emprego e satisfação no trabalho. Participaram da pesquisa trabalhadores com idade entre 18 e 65 anos, moradores de duas cidades diferentes da Alemanha, uma localizada na Alemanha Oriental e outra na Alemanha Ocidental, e as amostras variaram de 202 a 543 participantes. Os resultados das correlações apontaram correlações significativas com todas as variáveis, indo de 0,14 a 0,62 , exceto satisfação no trabalho, que apresentou baixa correlação.
Ainda na linha dos estudos que focam os antecedentes individuais, está a pesquisa de Sonnentag (2003), que examinou a relação entre resultados do trabalho, entre eles, comportamentos proativos e o grau de recuperação de energias dos empregados nos momentos de lazer. O estudo utilizou amostra de 147 empregados que preencheram um questionário e uma avaliação diária durante o período de 5 dias de trabalho consecutivos. A regressão multinível mostrou que o nível de recuperação diário afeta o nível comportamento proativo diário para além das variáveis personalidade proativa, características demográficas e características do trabalho. Além disso, foi verificado que a relação entre o nível de recuperação de energia e comportamento proativo é mediado pelo nível de envolvimento com o trabalho.

Incluída nos estudos que consideram antecedentes individuais e contextuais, encontra-se a pesquisa de Frese et al. (1996), que teve como objetivo principal comparar a iniciativa pessoal no trabalho entre a Alemanha Oriental e a Ocidental a partir de um estudo longitudinal. Amostras representativas de duas cidades foram obtidas. Os resultados confirmam a hipótese de que a iniciativa pessoal é mais baixa na Alemanha Oriental do que na Alemanha Ocidental em função do alto controle e da baixa complexidade no trabalho. Os alemães orientais sofrem uma supervisão mais restritiva, taylorista e burocrática do que os alemães ocidentais. Além disso, os dados sugerem que as diferenças se devem a fatores de socialização, e não de seleção.

Em 2001, Fay e Frese desenvolveram uma pesquisa sobre a validade do construto relacionando comportamento proativo com variáveis individuais (personalidade, cognição, conhecimento e competências, habilidades cognitivas e tendências comportamentais dos indivíduos de moderar especificidades do ambiente), organizacionais (controle e complexidade do trabalho, suporte organizacional e estressores) e comportamento e resultados individuais e 
organizacionais. Os resultados revelaram que a proatividade está relacionada consistentemente com necessidade de realização, falta de flexibilidade, orientação para a ação, qualificações do trabalho, habilidades cognitivas, autoeficácia, orientação para mudança, estratégias de enfrentamento, capacidade de lidar com erros e características do trabalho. Com relação aos consequentes de proatividade, foi encontrado um efeito sobre o desempenho individual e de pequenas firmas e sobre a lucratividade das firmas. O segundo estudo do artigo apresentou uma nova análise que avalia a influência de parâmetros motivacionais (controle de aspiração, autoeficácia e orientação para mudança) e habilidades cognitivas em iniciativa pessoal dentro de um estudo longitudinal na Alemanha Oriental. Os resultados mostram que habilidade cognitiva e orientações motivacionais determinam as mudanças em iniciativa pessoal de forma independente. As orientações motivacionais de controle de aspiração, autoeficácia e orientação para mudanças têm efeito de longo prazo sobre a iniciativa pessoal.

A pesquisa de Claes et al. (2005) relacionou a personalidade proativa com as dimensões de Hofstede, e foram encontrados dados de influência cultural sobre esse tipo de personalidade. Os autores sugerem que culturas com pouca distância do poder podem promover personalidade proativa, porque aumentam a responsabilidade pessoal e a inovação. O alto individualismo pode suportar a personalidade proativa desde que enfatize a iniciativa pessoal, a inovação e as atividades de ação. De acordo com esse raciocínio, os polos masculinidadefeminilidade contêm elementos que podem facilitar a personalidade proativa. Baixa evitação da incerteza pode tolerar a inovação e prever possíveis encorajamentos da personalidade proativa, e dinamismo e perseverança em orientação de longo prazo também podem facilitar a personalidade proativa. A Finlândia apresentou pouca distância do poder (que facilita a proatividade), pouca feminilidade (não está clara a relação com proatividade) e alto individualismo (que facilita a proatividade). Os belgas, situados entre os respondentes finlandeses e espanhóis, obtiveram escore médio em personalidade proativa. A Espanha mostrou forte evitação da incerteza (inibidor da proatividade) e uma orientação de curto prazo (inibidor da proatividade), por isso não surpreende o fato de ter obtido baixos escores de personalidade proativa.

Parker et al. (2006) desenvolveram uma pesquisa com o intuito de investigar se diferenças individuais e variáveis ambientais de trabalho afetam estados cognitivomotivacionais que, por sua vez, induziam o comportamento proativo. O modelo testou, como variável individual, a personalidade proativa, e como variáveis ambientais, a autonomia no trabalho, a confiança nos colegas e o suporte da chefia. Foram selecionados como estados cognitivo-motivacionais: autoeficácia, controle da situação, orientação para mudança e capacidade do funcionário de definir o seu trabalho de forma ampla, para além do conjunto de tarefas técnicas imediatas, tendo sido utilizada amostra de trabalhadores britânicos $(\mathrm{N}=282)$. Os resultados das equações estruturais mostraram que, com a exceção de suporte de supervisão, cada antecedente foi importante, embora por meio de diferentes processos. Os autores concluem que tanto a situação de trabalho quanto as diferenças individuais são relevantes para a emissão de comportamentos proativos, sendo essas relações mediadas por estados cognitivo-motivacionais.

Fischer e Smith (2006) desenvolveram uma pesquisa cujo objetivo era examinar se os valores moderavam a relação entre percepções de procedimentos de justiça e duas variáveis de resultado do trabalho (comprometimento organizacional e aspectos proativos de comportamento extrapapel). Nenhum efeito moderador foi encontrado para o comportamento extrapapel proativo, apesar de os valores de abertura a mudanças terem mostrado alta associação a relatos de comportamento proativo nas duas amostras 
da pesquisa, mas o conjunto dos valores não foi investigado, e esse aspecto não foi explorado pelos autores.

Em resumo, as variáveis individuais que constituem antecedentes de proatividade são: os traços de personalidade, a necessidade de realização, a necessidade de dominância, os valores, a falta de flexibilidade, a orientação para a ação, as qualificações do trabalho, as habilidades cognitivas, a autoeficácia, o envolvimento no trabalho, a orientação para mudança, as estratégias de enfrentamento, a capacidade de lidar com erros e as características do trabalho. No que diz respeito às variáveis organizacionais, destacam-se as características do trabalho e a cultura. Entretanto, destaca-se que poucos estudos têm investigado o efeito de variáveis contextuais.

Assim, não foram encontrados estudos que relacionassem valores pessoais e proatividade, mas há indícios de que os valores influenciam o comportamento proativo. A seguir, será apresentada a teoria de valores que embasa esta pesquisa.

\section{Valores pessoais}

A definição de valores dada por Schwartz e Bilsky é que são "princípios ou crenças sobre comportamentos ou estados desejáveis que transcendem situações específicas, que guiam a seleção ou a avaliação de comportamentos e eventos e que são ordenados por sua importância" (1987, p. 551).

A teoria de valores de Schwartz (1992) descreve aspectos da estrutura psicológica humana que são fundamentais e comuns a toda a humanidade. A teoria é embasada por três requisitos básicos universais da existência humana: 1) necessidades biológicas dos indivíduos como organismos biológicos, 2) requisitos de ação social coordenada e 3) necessidade de sobrevivência e de bemestar dos grupos. Esses três requisitos básicos representam o aspecto universal da teoria.

Assim como Kluckhohn (1951) e Rokeach (1973), Schwartz e Bilsky (1987) também consideram que os valores estejam organizados em um sistema e possuam conotação motivacional, e o que difere um valor de outro é o tipo de objetivo ou motivação que o valor expressa. Em 1992, Schwartz agrupou os valores em dez tipos motivacionais universais (autodeterminação, estimulação, hedonismo, realização, poder, segurança, conformidade, tradição, benevolência, universalismo). Esses dez tipos motivacionais estão organizados em uma estrutura circular, de forma que os tipos adjacentes representam motivações compatíveis, e os tipos em lados opostos representam conflito.

Os dez tipos podem ainda ser agrupados em uma estrutura mais parcimoniosa que contempla duas dimensões bipolares. A primeira dimensão contrapõe abertura a mudança (ênfase na independência de ação e pensamento) a conservadorismo (ênfase na autorrestrição pessoal que promove a preservação da estabilidade). A segunda dimensão contrapõe autotranscendência (busca pelo bem-estar dos outros) a autopromoção (busca de sucesso pessoal e de poder sobre os outros) (Schwartz, 1992).

Essa teoria já foi testada em mais de sessenta culturas, inclusive a brasileira, e os resultados têm dado apoio à proposição (Schwartz, 2005b; Tamayo \& Schwartz, 1993). Esse modelo teve o grande êxito de considerar a dinâmica dos valores na predição do comportamento, permitindo uma visão mais completa das motivações que sustentam as decisões, os julgamentos e o comportamento.

A relação entre os tipos motivacionais e os comportamentos no trabalho tem sido amplamente estudada no Brasil, com diversas pesquisas apontando o seu efeito sobre o comportamento (Mendonça \& Tamayo, 2005; Porto \& Tamayo, 2002; Tamayo, 2001, 2005). Parece factível, portanto, que as ações individuais sejam motivadas pelos valores, e eles constituem um antecedente a ser explorado nas pesquisas sobre comportamento humano. Assim, a seguir, será relatado o método desta pesquisa, 
que investigou o impacto dos valores na emissão do comportamento proativo.

\section{Método}

\section{Amostra}

Participaram do estudo 369 funcionários de empresas públicas (6\%) e privadas (94\%). Das empresas privadas, 54\% eram nacionais, e $71 \%$, do ramo de serviços. Com relação aos dados demográficos, $56 \%$ da amostra pertenciam ao sexo feminino, $61 \%$ tinham idade entre 21 e 40 anos, 34\% possuíam o grau superior e 53\% eram pós-graduados. Com relação ao tempo de serviço, 54\% estavam entre o primeiro e quinto ano de trabalho na empresa, e $61 \%$ não ocupavam cargo de chefia.

\section{Instrumentos}

Foram utilizadas a Escala de Comportamento Proativo nas Organizações (ECPO), desenvolvida e validada por Kamia e Porto (2009), e a Escala de Valores Pessoais (PVQ), desenvolvida por Schwartz (2005a) e validada por Tamayo e Porto (2009). A ECPO é composta por 27 itens, e a estrutura unifatorial obteve alpha de Cronbach de 0,95 . O PVQ é composto por 40 itens que avaliam os tipos motivacionais propostos por Schwartz (1992).

\section{Procedimentos}

A pesquisa foi disponibilizada em um site na internet, e a coleta de dados foi realizada pelo mesmo veículo. Dessa forma, os funcionários tiveram a liberdade de responder ao questionário quando tivessem disponibilidade. Entretanto, cabe ressaltar que não foi feito controle sobre quem poderia responder o questionário, assim, outras pessoas podem tê-lo feito. O retorno obtido foi de $31 \%$ dos questionários enviados. Nesta pesquisa, foram considerados apenas os questionários respondidos por funcionários de empresas públicas e privadas.

Antes da análise de correlação e regressão múltipla, os dados foram examinados quanto ao número de casos omissos, de casos extremos e no que se refere à normalidade dos fatores. Como o questionário aplicado via internet não permitia que o respondente passasse para a próxima página sem ter preenchido todos os itens, não houve casos omissos. Os 44 casos extremos univariados foram identificados por meio do escore Z. Após todas as eliminações, o banco de dados ficou composto por 325 observações. O teste de Kolmogorov e Smirnov indicou distribuição normal e alta significância para o fator proatividade ( $p>0.05$ ).

Realizou-se, posteriormente, a transformação dos dados, conforme sugerido por Schwartz (2005b) para correção no uso da escala de valores. Dessa forma, em vez de se trabalhar utilizando o escore bruto dos dados, prosseguiu-se utilizando o desvio de cada fator em relação à média geral do indivíduo, calculando-se a média de importância de cada indivíduo para os 40 itens. Ainda seguindo a orientação de Schwartz, a correlação parcial foi utilizada para correlacionar prioridades axiológicas com a variável proatividade, sendo a parcialização feita com a média de julgamentos. O teste de Kolmogorov e Smirnov indicou distribuição normal para os fatores da PVQ.

A linearidade entre a proatividade e as variáveis de valores foi analisada por meio dos gráficos interativos Scatterplot, do SPSS. Os resultados apontaram relações lineares entre as variáves, exceto para a variável poder/ realização. A colinearidade entre as variáveis foi analisada por meio do diagnóstico de colinearidade do módulo regressão do SPSS. A variável poder/realização indicou multicolinearidade, e, por esse motivo, a variável foi retirada da análise, além da sua relação com proatividade ser praticamente nula. 


\section{Resultados}

A matriz de correlação parcial entre comportamento proativo e valores pessoais revela que somente os tipos motivacionais estimulação e tradição apresentaram correlação significativa com proatividade (Tabela 1), sendo que a relação com estimulação é positiva, e com tradição, negativa.

Tabela 1. Matriz de correlação parcial

\begin{tabular}{|c|c|c|c|c|c|c|c|c|}
\hline Variáveis & $\begin{array}{l}\text { Compor- } \\
\text { tamento } \\
\text { Proativo } \\
\text { (VD) }\end{array}$ & $\begin{array}{l}\text { Universa- } \\
\text { lismo/ } \\
\text { Benevo- } \\
\text { lência }\end{array}$ & $\begin{array}{l}\text { Hedonismo/ } \\
\text { Autode- } \\
\text { terminação }\end{array}$ & Segurança & $\begin{array}{l}\text { Estimu- } \\
\text { lação }\end{array}$ & $\begin{array}{l}\text { Confor- } \\
\text { mismo }\end{array}$ & Tradiç̧ão & $\begin{array}{l}\text { Poder/ } \\
\text { Realiza- } \\
\text { ção }\end{array}$ \\
\hline $\begin{array}{l}\text { Universalismo/ } \\
\text { Benevolência }\end{array}$ & .100 & 1.000 & & & & & & \\
\hline $\begin{array}{l}\text { Hedonismo/ } \\
\text { Autodeter- } \\
\text { minação }\end{array}$ & .006 & $-.234^{* *}$ & 1.000 & & & & & \\
\hline Segurança & .052 & .084 & $-.398^{* *}$ & 1.000 & & & & \\
\hline Estimulação & $.176^{* *}$ & $-.223^{* *}$ & $.312^{* *}$ & $-.285^{* *}$ & 1.000 & & & \\
\hline Conformismo & $-.081^{* *}$ & -.037 & $-.454^{* *}$ & ,066 & $-.393^{* *}$ & 1.000 & & \\
\hline Tradição & -.183 & ,091 & $-.355^{* *}$ & ,053 & $-.291^{* *}$ & $.321^{* *}$ & 1.000 & \\
\hline $\begin{array}{l}\text { Poder/ } \\
\text { Realização }\end{array}$ & -,027 & $-594 * *$ & ,077 & $-255^{* *}$ & ,042 &,$- 247^{* *}$ &,$- 493^{* *}$ & 1000 \\
\hline Média &, 510 &, 561 & ,420 & , 167 &,- 357 &,- 090 &,- 947 &,- 448 \\
\hline Desvio-padrrão & 811 &, 404 & ,486 & ,608 & 850 &, 517 & 695 & ,646 \\
\hline
\end{tabular}

Fonte: dados da pesquisa

${ }^{* *} \mathrm{p} \leq 0.01$

Conforme previsto em teoria (Schwartz, 2005b), o modelo circular, que contém os tipos motivacionais e as relações de congruência e antagonismo, surge por meio das análises de correlação entre os tipos motivacionais e os comportamentos proativos, e pode ser visto na Figura 1.

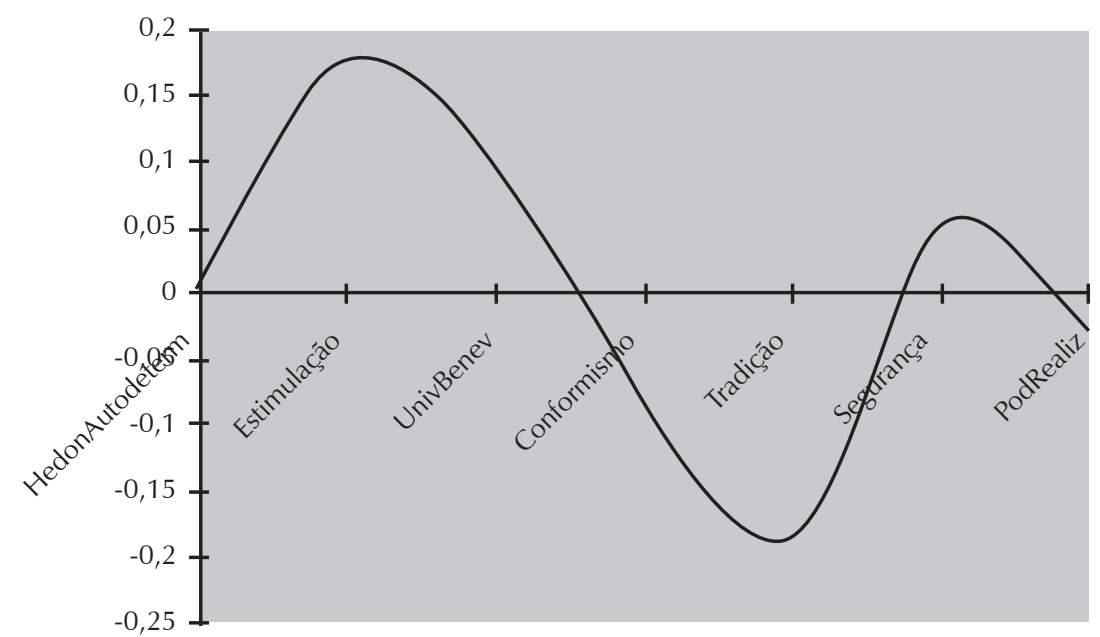

Figura 1. Gráfico da curva sinusoidal resultante das análises mostrando as relações entre os tipos motivacionais e os comportamentos proativos.

Fonte: dados da pesquisa

Os resultados da regressão linear múltipla podem ser visualizados na Tabela 2. Os valores pessoais explicaram apenas $8 \%$ da variância do comportamento proativo, o que exprime baixo poder de predição das variáveis independentes. A análise dos valores absolutos dos coeficientes de regressão padronizados permite-nos concluir que a 
variável estimulação $(\beta=0,214)$, seguida de tradição $(\beta=-0,163)$ e universalismo/ benevolência ( $\beta=0,150$ ), são as que apresentam maiores contribuições relativas para explicar o comportamento proativo. Esses resultados serão discutidos a seguir.

Tabela 2 . Resultados da regressão linear múltipla dos valores pessoais sobre os comportamentos proativos

\begin{tabular}{lll}
\hline & B & $\beta$ \\
\hline Universalismo/Benevolência &, $302^{* *}$ &, 150 \\
Hedonismo/Autodeterminação &,- 043 &,- 026 \\
Segurança &, 128 & 0,096 \\
Estimulação &, $205^{* *}$ &, 214 \\
Conformismo &, 068 &, 043 \\
Tradição &,$- 189^{* *}$ &,- 163 \\
& Constante $=4,827$ & \\
& $\mathrm{R}^{2}=, 084$ & \\
& $\mathrm{R}^{2}$ ajustado $=, 067$ & \\
& $\mathrm{R}=, 290$ & \\
\hline
\end{tabular}

Fonte: dados da pesquisa

** $\mathrm{p} \leq 0.01$

\section{Discussão}

As análises estatísticas utilizadas para testar o modelo permitiram visualizar a disposição dos valores dentro do modelo circular proposto pela teoria de Schwartz (1992). Os resultados evidenciaram a existência de relações de oposição entre as dimensões antagônicas de autotranscendência versus autopromoção e também entre as dimensões abertura a mudança versus conservação. As dimensões autotranscendência e autopromoção apresentaram sinais opostos, como previsto na teoria, apesar de não significativos. Os polos de conservação e abertura a mudança também apresentaram sinais antagônicos.

Os resultados apresentados pela presente pesquisa dão suporte à hipótese de que os valores pessoais se relacionam com o comportamento proativo. O tipo motivacional que apresentou relação mais forte com o comportamento proativo foi o tipo estimulação, seguido do tipo antagônico, tradição, que se relacionou negativamente.
Os valores de estimulação, que pertencem à dimensão de abertura a mudança, foram os que apresentaram correlação significativa mais forte com o comportamento proativo, o que confirma em parte os resultados obtidos na pesquisa de Fisher e Smith (2006). Essa correlação se deve ao fato de que os valores de estimulação representam objetivos motivacionais que envolvem excitação, ousadia e desafio na vida, requisitos necessários para uma das principais características do comportamento proativo, que é a realização de ações de mudança orientadas por metas de longo prazo. Para que tais ações se concretizem, é necessário que o indivíduo não se intimide em expor suas ideias em diversas situações, desafiando o status quo, que não tenha medo de mudanças e busque novidades, e que não tenha medo de errar. Essa ousadia e gosto pela novidade e o desafio de propor mudanças de melhoria podem ser observados no comportamento proativo.

Opostos à estimulação estão os valores de tradição, que obtiveram a maior correlação negativa com o comportamento proativo. Os valores de tradição têm como objetivo motivacional o respeito, o compromisso, a moderação, a devoção, a aceitação dos costumes e a vida espiritual, que são opostos aos valores de estimulação, portanto, antagônicos ao comportamento proativo.

Os valores de universalismo e benevolência apresentaram o segundo maior impacto na predição do comportamento proativo. Tal resultado pode indicar que as metas organizacionais relacionadas ao comportamento proativo não se limitam ao crescimento financeiro. As metas, ao contrário, extrapolam esse limite, englobando o bemestar dos colegas e a preservação do ambiente organizacional e da natureza. Valores de universalismo envolvem a compreensão, o agradecimento, a tolerância e o bem-estar de todas as pessoas e da natureza. Estudos futuros devem investigar se essa relação se mantém.

Os resultados oferecem suporte para a predição, porém com um poder preditivo baixo. Essa baixa 
predição confirma os resultados encontrados por Kristiansen e Hotte (1996), que, ao analisarem um conjunto de pesquisas que relacionavam valores-atitudes-comportamentos, perceberam que o poder preditivo dos valores sobre o comportamento era muito baixo. A suposição dos autores para explicar os baixos valores de predição dar-se-ia pela existência de diversas variáveis moderadoras que afetariam o impacto dos valores sobre o comportamento. Ros (2006) também concorda que a relação valores e comportamento não é uma relação direta, e sim, mediada pelas atitudes, e também não descarta que variáveis como normas subjetivas, normas pessoais, controle percebido, desejo, intenção, frequência ou não da ação no passado e autoconceito afetam a relação entre valores e comportamento.

Como se pode perceber, a relação entre valores e comportamento é algo complexo que, segundo estudos anteriores, envolve outras variáveis. Entretanto, o foco principal deste estudo é o poder preditivo dos valores, e não as variáveis que afetam essa relação, e, dessa forma, é possível afirmar que os valores pessoais influenciam o comportamento proativo, apesar de outras variáveis também serem importantes para explicar esse comportamento. Considerando que os comportamentos nas organizações são altamente normativos, o fato de os valores predizerem pro-atividade é um indicativo de que os interesses individuais são relevantes para sua compreensão.

\section{Conclusão}

O objetivo geral desta pesquisa foi investigar o poder preditivo dos valores pessoais sobre $\mathrm{o}$ comportamento proativo. Conclui-se que esse tipo de comportamento está positivamente relacionado com objetivos motivacionais que envolvem excitação, ousadia e desafio na vida, isso porque a expressão de comportamentos proativos requer coragem para expor ideias em diversas situações, para desafiar o status quo e para não temer mudanças e buscar novidades. Este estudo também demonstrou que as metas do comportamento proativo extrapolam o crescimento financeiro da organização, envolvendo também o bem-estar dos colegas e a preservação do ambiente organizacional e da natureza, fato que pode ser observado pela correlação positiva com os valores de universalismo e benevolência. Por outro lado, os resultados mostraram que o comportamento proativo é antagônico aos valores do tipo tradição, que envolvem a moderação, a devoção, a aceitação dos costumes e a vida espiritual.

Apesar dessas contribuições, cabe ressaltar algumas limitações do estudo. A primeira delas refere-se à amostra que, por ter sido por conveniência, pode apresentar vieses como, por exemplo, pessoas mais proativas ou mais interessadas pelo estudo podem ter respondido o questionário. Verifica-se, porém, que houve variabilidade das respostas, o que pode não ter comprometido os dados. Mesmo assim, seria interessante que estudos futuros verificassem a adequação da estrutura para outras amostras. Além disso, a amostra selecionada é composta principalmente por indivíduos com grau superior completo e por pós-graduados, sendo necessária uma validação com amostra composta por pessoas com menor grau de escolaridade. Por fim, ressalta-se a limitação de que o envio dos questionários por email não permite controle sobre quem responde o questionário e, eventualmente, outras pessoas que não as originalmente selecionadas podem tê-lo respondido. Entretanto, como a participação era voluntária, não houve pressão para que os participantes selecionados encaminhassem a mensagem a outras pessoas.

Sugestões para estudos futuros incluiriam a realização de pesquisa que envolvesse outras variáveis mediadoras e moderadoras entre valores e comportamento e variáveis do contexto organizacional, como, por exemplo, normas e políticas organizacionais, atitudes e cultura organizacional, entre outros. Dessa forma, seria interessante desenvolver modelos que investigassem de que forma características organizacionais em sintonia com os valores dos indivíduos podem promover maior proatividade. 


\section{Referências}

\section{Meiry Kamia}

Consultora Organizacional, Hipnoterapeuta Ericksoniana, Pesquisadora com foco em Comportamento Organizacional, Valores Humanos e Psicodrama. Mestre em Administração pela Universidade Presbiteriana Mackenzie,

São Paulo, SP- Brasil.

E-mail: meiry@hvalue.com.br

\section{Juliana Barreiros Porto}

Doutora em Psicologia pela Universidade de Brasília, Professora adjunta do Departamento de Psicologia Social e do Trabalho e do programa de pós-graduação em Psicologia Social, do Trabalho e das Organizações da Universidade de Brasília, Brasília - DF - Brasil.

E-mail: porto.juliana@gmail.com

Endereço para envio de correspondência:

Rua manuel gaya, 1759 - cs 03 - Vila Mazzei, São Paulo, SP - Brasil. CEP: 02.313-001

Recebido 29/1/2010, 1ạ Reformulação 31/1/2011, Aprovado 5/5/2011.

Bateman, T. S., \& Crant, J. M. (1993). The proactive component of organizational behavior: A measure and correlates. Journal of Organizational Behavior, 14, 103-118.

Bateman, T. S., \& Crant, J. M. (1999, may/june). Proactive behavior: Meaning, impact, recommendations. Business Horizons, 42(3), 63-70.

Claes, R., Beheydt, C., \& Lemmens, B. (2005). Unidimensionality of abbreviated proactive personality scales across cultures. Applied Psychology: An International Review, 54(4), 476-489.

Crant, J. M. (1996, july). The proactive personality scale as a predictor of entrepreneurial behavior. Journal of Small Business Management, 34, 42-49.

Crant, J. M. (2000). Proactive behavior in organizations. Journal of Management, 26(3), 435-462.

Fay, D., \& Frese, M. (2001). The concept of personal initiative: An overview of validity studies. Human Performance, 14(1), 97-124.

Fischer, R., \& Smith, P. B. (2006). Who cares about justice? The moderating effect of values on the link between organisational justice and work behaviour. Applied Psychology, 55(4), 541-562.

Frese, M., Fay, D., Hilburger, T., Leng, K., \& Tag, A. (1997). The concept of personal initiative: Operationalization, reliability and validity in two German samples. Journal of Occupational and Organizational Psychology, 70, 139-161.

Frese, M., Kring, W., Soose, A., \& Zempel, J. (1996). Personal iniciative at work: Differences between East and West Gemany. Academy of Management Journal, 39(1), 37-63.

Frese, M., Teng, E., \& Wijnen, C. J. D. (1999). Helping to improve suggestion systems: Predictos of making suggestions in companies. Journal of Organizational Behavior, 20, 1139-1155.

Jong, A., \& Ruyter, K. (2004). Adaptative versus proactive behavior in service recovery: The role of self-managing teams. Decisions Sciences, 35(3), 457-491.

Kamia, M., \& Porto, J. B. (2007). Desenvolvimento e validação da Escala de Comportamento Proativo nas Organizações. In 31 Encontro da Associação Nacional de Pós-graduação e Pesquisa em Administração - EnANPAD, Rio de Janeiro.

Kamia, M., \& Porto, J. B. (2009). Desenvolvimento e validação da Escala de Comportamento Proativo nas Organizações - ECPO. Revista de Avaliação Psicológica, 8(3), 359-367.

Kluckhohn, C. K. M. (1951). Values and value orientation in the theory of action. In T. Parsons, \& E. Shilds (Orgs.), Toward a general theory of action (pp. 388-433). Cambridge: Harvard University Press.

Kristiansen, C. M., \& Hotte, A. M. (1996). Morality and the self: Implications for the when and how of value-attitude-behavior relations. In C. Seligman, J. M. Olson, \& M. P. Zanna (Orgs.), The psychology of values:The Ontario symposium (Vol. 8, pp. 77-106). Ontario: Lawrence Erlbaum Associates, Inc.
Mendonça, H., \& Tamayo, A. (2005). Valores e retaliação organizacional. In A. Tamayo, \& J. B. Porto (Orgs.), Valores e comportamento nas organizações. Rio de Janeiro: Vozes.

Parker, S. K., Williams, H. M., \& Turner, N. (2006). Modeling the antecedents of proactive behavior at work. Journal of Applied Psychology, 91(3), 636-652.

Porto, J. B., \& Tamayo, A. (2002). Prioridades axiológicas e regiões brasileiras: preditores de civismo nas organizações. Psicologia: Organizações e Trabalho, 2, 31-57.

Rank, J., Pace, V. L., \& Frese, M. (2004). Three avenues for future research on creativity, innovation, and initiative. Applied Psychology: An International Review, 53(4), 518-528.

Rokeach, M. (1973). The nature of human values. New York: The Free Press.

Ros, M. (2006). Valores, atitudes e comportamento: uma nova visita a um tema clássico. In M. Ros, \& V. V. Gouveia (Orgs.), Psicologia social dos valores humanos. São Paulo: Senac.

Schwartz, S. H. (1992). Universals in the content and structure of values: Theoretical advances and empirical tests in 20 countries. In M. P. Zanna (Ed.), Advances in experimental social psychology (Vol. 24, pp. 1-65). San Diego: Academic.

Schwartz, S. H. (2005a). Validade e aplicabilidade da teoria de valores. In A. Tamayo, \& J. B. Porto (Orgs.), Valores e comportamento nas organizações (pp. 56-95). Petrópolis, RJ: Vozes.

Schwartz, S. H. (2005b). Valores humanos básicos: seu contexto e estrutura inter-cultural. In A. Tamayo, \& J. B. Porto (Orgs.), Valores e comportamento nas organizações. Rio de Janeiro: Vozes.

Schwartz, S. H., \& Bilsky, W. (1987). Toward a universal psychological structure of human values. Journal of Personality and Social Psychology, 53, 550-562.

Sonnentag, S. (2003). Recovery, work engagement, and proactive behavior: A new look at the interface between nonwork and work. Journal of Applied Psychology, 88(3), 518-528.

Tamayo, A. (2001). Prioridades axiológicas, atividade física e estresse ocupacional. RAC, 5(3), 127-147.

Tamayo, A. (2005). Impacto dos valores pessoais e organizacionais sobre o comprometimento organizacional. In A. Tamayo, \& J. B. Porto (Orgs.), Valores e comportamento nas organizações (pp. 160-186). Rio de Janeiro: Vozes.

Tamayo, A., \& Porto, J. B. (2009). Validação do questionário de perfis de valores (QPV) no Brasil. Psicologia: Teoria e Pesquisa, 25(3), 369-376.

Tamayo, A., \& Schwartz, S. (1993). Estrutura motivacional dos valores. Psicologia: Teoria e Pesquisa, 9, 329-348. 